\title{
Port Energy Supply Through An LNG-Powered Integrated Grid
}

\author{
Davide Borelli ${ }^{1}$, Francesco Devia $^{1}$, Corrado Schenone ${ }^{1}$, Federico Silenzi $^{1{ }^{1,}}$ and Luca \\ Tagliafico $^{1}$ \\ ${ }^{1}$ Università degli Studi di Genova, DIME sez. TEC, Via all’Opera Pia 15a, Genova, 16145, Italy
}

\begin{abstract}
Ports are primary importance infrastructures when considering the transportation of people and goods across the planet. Two of the biggest issues linked to harbor areas are the pollutant emissions from moored ships, as well as the huge energy demand coming from ships and other activities that take place inside of the port boundaries. To tackle these challenges, the effort on the ship-side is to promote the transition to Liquefied Natural Gas (LNG) propulsion, while on the harbor-side is to implement electrical ship feeding. In general, using LNG for bunkering purposes implies its storage onshore using dedicated tanks. The regasification of LNG in situ can be exploited to cool down a water-brine flow (i.e. ethyl-alcohol and water). The cold brine can be used to increase the efficiency of a standard inverse cycle to produce cold (i.e. $-30^{\circ} \mathrm{C}$ ) used for refrigeration purposes inside ports. Then, the NG flow can be used to produce electrical energy with a standard turbogas cycle with energy recovery from flue gases. The generated electricity directly runs the standard inverse cycle with ethyl-alcohol and water brine to completely fulfill the energy demand for cold thermal power. The electricity still available is then used to supply the onboard systems of moored ships, or otherwise is sold to the users operating in the port. The flue gas coming from the turbogas plant can be used to provide both heating and process heat, through a dedicated heat exchanger and a natural gas boiler. The new envisaged plant can exploit all possible useful effects coming from the regasification process, helping to push towards a greener energy management system in harbor areas, through smart operative integration of the several available energy systems and the implementation of efficient energy smart grids.
\end{abstract}

*Corresponding author: federico.silenzi@edu.unige.it, 


\section{Introduction and litterature review}

Liquefied Natural Gas (LNG) is a crucial factor when dealing with the transition from the actual fossil fuel dominated economy towards a more green and sustainable future development [1]. During the past years the importance of LNG has increased: considering the global LNG trade in 2019, it increased by 40.93 MT (+13\%) if compared to 2018, confirming the positive trend of growth for the sixth consecutive year [2]. Also, the regasification capacity increased from 2018 to 2019, reaching a total of 821 MTPA (in February 2020) [2].

LNG is the common name given to natural gas in its liquid form. Natural gas is cooled down to cryogenics conditions $\left(-160^{\circ} \mathrm{C}\right)$, increasing its energy density, in order to allow for cheaper storage and transport. Before the local distribution, the LNG must be regasified in dedicated plants. The standard regasification technologies imply the use of an external energy source (i.e. seawater, external burners, etc.), usually wasting the available exergy. With the increasing importance of energy efficiency topics, new technologies demand for the energy recovery of the regasification process to produce multiple beneficial effects. Different solutions have been proposed during the years for this purpose. Dispenza et al. (2009) [3] proposed a CHP plant using special heat exchangers employing helium as exchanging fluid. Tagliafico et al. (2013) [4] quantified the energy savings related to the integration of an LNG vaporization facility with two different power generation systems: a gas turbine and a cogenerative combined steam power plant.

More recently, Fahmy et al. (2015) [5] studied different regasification plant configurations, in order to assess which one provided the best solution in terms of $C_{4}^{+}$ concentration.

Li et al. (2017) [6] proposed an LNG cold warehouse system, analyzing and assessing its thermal performance. Kanbur et al. (2017) [7] reviewed the different technological applications to which the regasification energy recovery can be applied (i.e. power generation, cryogenic carbon dioxide capture, separation processes, cold food storage, etc).

Marquez et al. (2018) [8] reviewed the available technologies for regasification and modeled a polygeneration plant for power production and cold generation feeding a district cooling network. In 2019, Lee et al. [9] studied the application of LNG direct expansion coupled with innovative cold energy storage, giving insight about its energy optimization and exergy analysis. Marquez et al. (2019) [10] proposed and analyzed the performance of a Combined Cold and Power (CCP) plant. The researchers modeled the plant using real operation data, benchmarking its performance against that of a cryogenic power plant at different operating conditions.

He et al. (2019) [11] reviewed different LNG cold energy exploitation system, providing insights about future applications, as well as discussing limitations and challenges about the application of such technologies. In a recent paper, Ayoua et al. (2020) [12] described the possibility of exploiting the waste LNG exergy for multigeneration purposes, using two different plant solutions (Brayton and Rankine based cycles). The researches proved the possibility of both energy savings and $\mathrm{CO}_{2}$ emissions reduction.

Liquefied Natural Gas can be an essential resource also to tackle environmental pollution in the transport sector. While LNG automotive applications are already widespread in the terrestrial vehicle market, the same does not apply to the marine sector. The majority of existing vessels are fueled using standard fossil fuels (heavy oils and crude derivates), with considerable impacts on air pollution.

In response to this, the International Maritime Organization introduced some Emission Control Areas (ECAs), designated under regulation 13 of MARPOL Annex VI [13]. Also, the European Parliament has outlined the importance of reducing ship emissions, with the Directive (EU) 2018/410 [14]. 
Liquefied Natural Gas can be used as an effective solution to overcome the pollution emissions of ships, using it as an alternative fuel for marine transports. Yoo (2017) [15] carried out an extensive economic assessment about using LNG as an alternate marine fuel for $\mathrm{CO}_{2}$ carriers. Fokkema et al. (2017) [16] discussed an investment appraisal method to compare conventional vessels with LNG fueled ships. More recently, Iannacone et al. (2020) [17] compared the use of LNG against the use of diesel oil when cruise ship fuel systems are investigated, finding that the use of LNG is more sustainable than standard marine fuel technologies.

In this framework, it is clear that the presence of LNG bunkering tanks inside seaports can be capitalized. In the present article, a new envisaged plant layout is proposed. Cold power for refrigeration purposes, hot thermal power for steam generation or district heating, and electrical power available for cold ironing are possible energy outputs made available by means of the exergy recovery during the regasification.

\subsection{Energy Demand in Ports}

In this paragraph, some data regarding energy demands in ports is reported. These data have been acquired and processed as part of a European Project about the use of LNG in seaports. The SIGNAL (Strategie transfrontalIere per la valorizzazione del Gas NAturale Liquido) project [18] is still work in progress, so it is not possible to disclose sensible data. However, the aggregated results can be useful in order to assess the importance of exploiting the Liquefied Natural Gas in seaports. The data were acquired for one of the principal seaports of the North Mediterranean area.

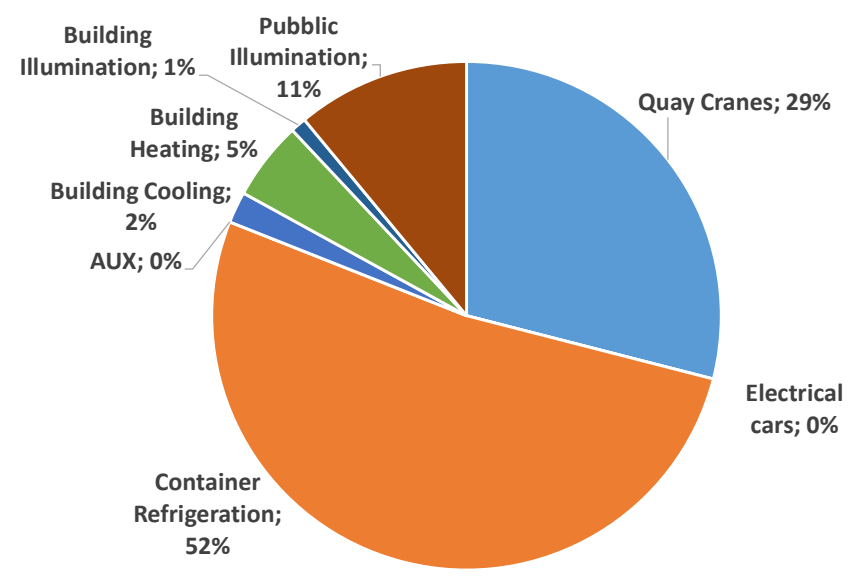

(a) 


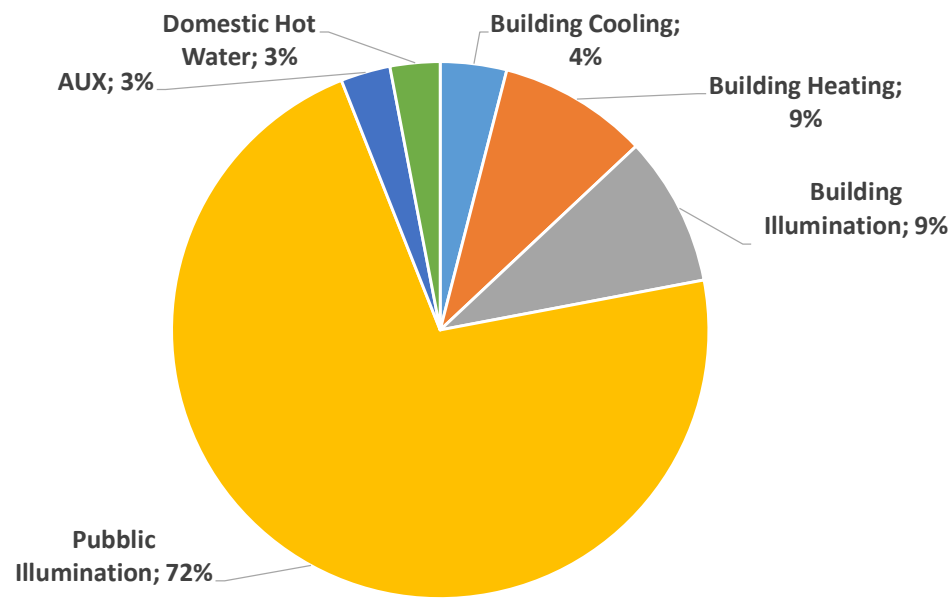

(b)

Fig 1. (a) Distribution of electricity consumption including container refrigeration and container handling with electric cranes - (b) Primary energy demand related to offices and the external areas illumination

\section{Model description}

In the framework described, the present paper deals with the proposal of a plant layout able to satisfy different energy needs in seaport areas. In particular, the presence of a Liquefied Natural Gas (LNG) tank inside ports is capitalized, in order to create an integrated energy network that can exploit the cold exergy available during the LNG regasification process to produce chilled water, electricity and thermal power. Those energy fluxes can be coupled with the productive activities that are often present in docks and seaports areas.

The proposed new plant is a stand-alone system, wholly developed and tuned for the seaport areas, able to satisfy the following energy needs:

- Cold Thermal Power: available at a temperature of $-30{ }^{\circ} \mathrm{C}$, the cold power line (up to $800 \mathrm{~kW})$ can be used to satisfy different necessities, like deep-freeze $\left(-30^{\circ} \mathrm{C}\right)$ and low-temperature $\left(-20^{\circ} \mathrm{C}\right)$ food treatment, refrigeration $\left(-5{ }^{\circ} \mathrm{C}\right)$, cold warehouses for perishable goods $\left(+5^{\circ} \mathrm{C}\right)$. In case no alimentary process industries are present, the cold power line can be used to produce district cooling for buildings and offices conditioning;

- Hot Thermal Power: possibly available at different temperatures (i.e. $70-80{ }^{\circ} \mathrm{C}$ for district heating of buildings or $110^{\circ} \mathrm{C}$, process steam line), it can be used to feed the industrial processes in the area, as well as conditioning systems or absorption chillers;

- Electrical Power Production: up to $12 \mathrm{MW}$, mainly aimed to provide electrification of berths to feed moored ships (cold-ironing). The capacity is designed to be able to fully sustain the electrical system of cruise ships and different kind of vessels; 
- Bunkering: the LNG can be directly used to provide refueling for new generation ships, that can operate using natural gas;

- $\mathrm{CNG}$ automotive applications: the $\mathrm{LNG}$ can be used to provide a CNG line, dedicated to the refueling of trucks and operating machines, including also new generation vehicles equipped with fuel cell systems.

At this point, it is possible to describe the energy plant, introducing all the main apparatuses, and giving an overall insight of the system layout, (ref. Fig 2).

The LNG is stocked in a dedicated tank, at cryogenic conditions $\left(-160{ }^{\circ} \mathrm{C}, 1.14\right.$ bar). The tank is used mainly to provide LNG for the bunkering service and automotive purposes (the refueling of trucks and operating machines). The presence of LNG in seaports is an excellent opportunity for exploiting the significant amount of exergy available during regasification. For this purpose, part of the LNG stored in the tank can be regasified and used to produce electrical energy, cold thermal power, and heat. The total capacity of the proposed plant would be $1.8 \cdot 10^{7} \mathrm{Sm}^{3} /$ year (Standard Conditions $=0{ }^{\circ} \mathrm{C}$ and $101.3 \mathrm{kPa}$ ).

A stream of LNG is extracted from the tank and it is circulated using a pump (LNG pump), which is used to raise the pressure of the LNG flow from the tank pressure (1.14 bar) to a pressure value suitable for the feeding of the combustion chamber ( 5 bar). The use of a circulation pump to raise the LNG pressure while it is still in liquid phase is a favorable choice that aims to reduce the energy needed to compress the gas before the combustion chamber. The boil-off gas is collected from the LNG tank upper part, it is compressed (by the compressor GC1) up to 5 bar, and it is sent to the main LNG line. The mass flow rate of the LNG line is sufficiently high to guarantee the condensation of the boil-off gas as soon as the two streams mix.

The phase change (vapor to liquid) occurs inside the first heat exchanger (HX1). The HX1 is used to lower the temperature of a brine (Ethyl Alcohol and water) secondary loop. The brine flow functions as a heat sink for a direct expansion refrigeration cycle, allowing the production of cold thermal power that can be used, for instance, by a low-temperature food treatment plant.

After the phase change that takes place inside the first heat exchanger, the gas (Natural Gas) flows inside a second heat exchanger (HX2): here, the inlet air used to feed the combined gas cycle plant is chilled and dehumidified. Lowering the temperature of the airstream is of paramount importance to reduce the compressor (GC2) work needed to raise the pressure of the air entering the combustion chamber (CC). Moreover, the dehumidification is useful to enhance the thermal performance of the thermal conversion of the gas cycle. After passing inside $\mathrm{HX} 2$, the gas stream raises its temperature, and it is ready to be circulated through a third heat exchanger (HX3). This component is useful for achieving two goals: the first is to furtherly heat the NG stream before entering the combustion chamber. The second is to help lowering the temperature of the flue gas stream coming from the gas cycle turbine (GC turbine).

The next component is a three-way valve (VL1) that can be used to spill part of the methane to feed an auxiliary boiler (BO). The boiler is used to integrate the heat required by the district heating or the service steam loop $\dot{Q}_{h}(\tau)$, assuring that the thermal requests are always fulfilled.

After the three-way valve, the natural gas is burned, together with the feeding air, inside the combustion chamber. The hot flue gases are used to operate the turbine of the combined gas cycle, producing electricity $\left(P_{E L}(\tau)\right)$. The electrical power produced can be used for cold ironing purposes, but can also be used for self-consumption purposes, when conditions are favorable. 
The turbine is also used to power the main compressor (GC2), which is necessary to increase both the pressure and the temperature of the airstream feeding the combustion chamber.

After the combustion, the flue gases are circulated inside a thermal recuperator (HX4), which is fundamental for increasing the thermal efficiency conversion of the entire plant. Inside HX4, the energy recovered from the flue gases is used to increase the temperature of the feeding air entering the combustion chamber significantly.

After the recuperator, the flue gases are converged towards another heat exchanger (HX5), which is necessary to furtherly lower the temperature of the exhausts before discharging them. The thermal energy recovered is used to preheat the water entering the boiler (BO), contributing to reduce the amount of natural gas spilled with the three-way valve (VL).

Before being released into the environment, the flue gases are conveyed into HX3, which has already been described.

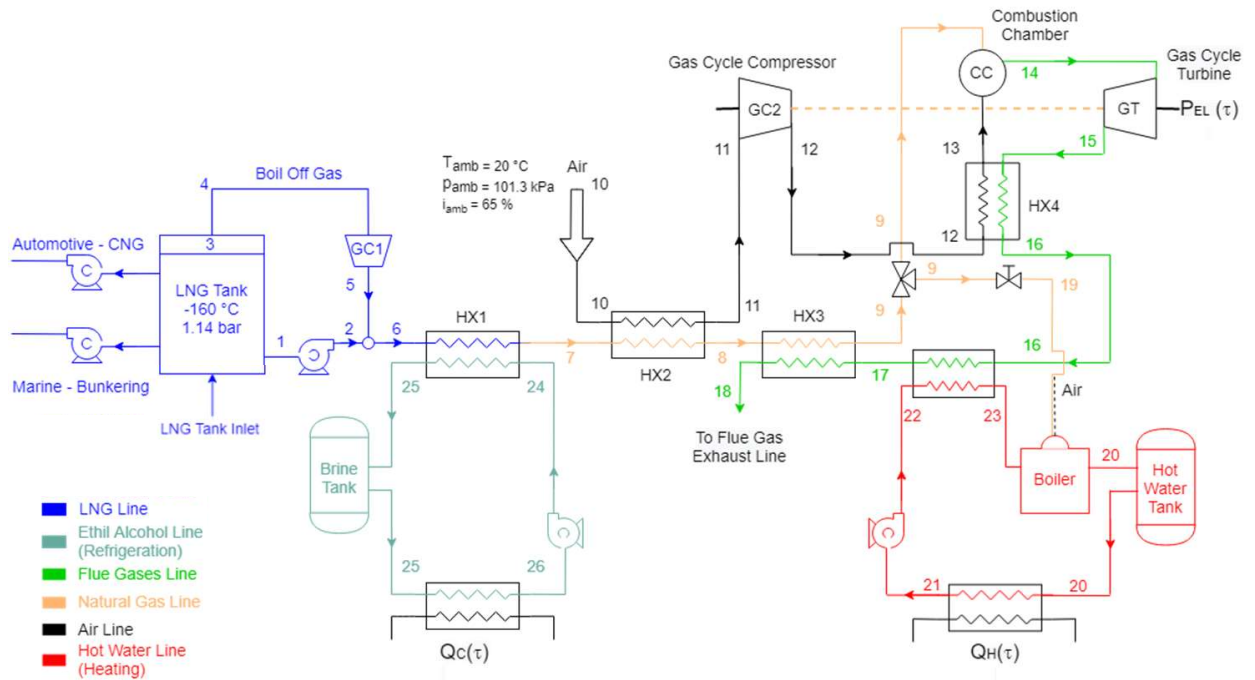

Fig 2: LNG cogenerative multipurpose plant layout

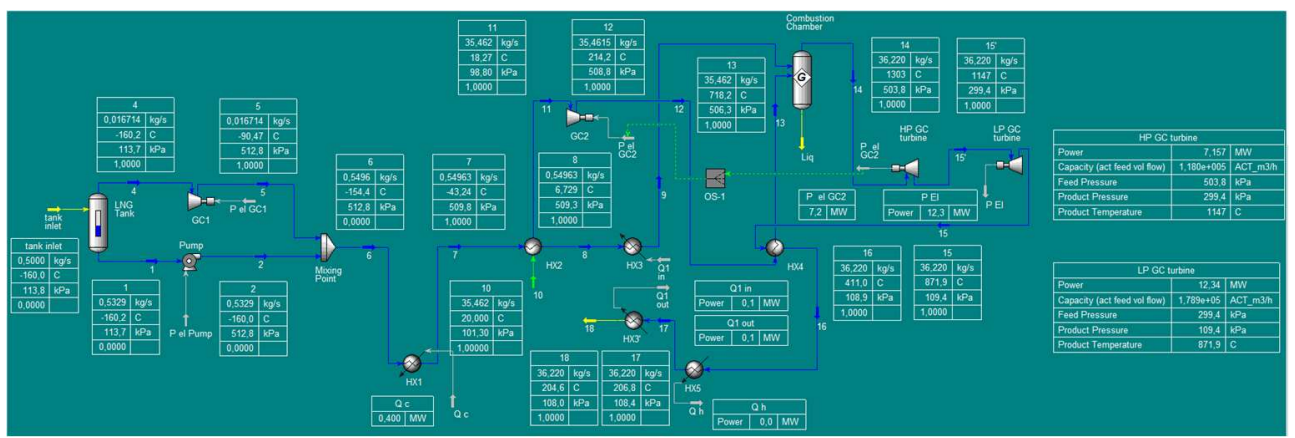

Fig 3: Plant Layout as it is implemented in Honeywell's UniSim ${ }^{\circledR}$ Design Suite - the tables represent the fluid thermodynamical conditions when the model is running. 


\section{Model Implementation}

The plant layout described in the previous paragraph has been simulated using the dynamic software UniSim ${ }^{\circledR}$ Design Suite by Honeywell. At this stage of work, some simplifications have been introduced, to focus the analysis on the natural gas plant network.

It is considered the stationary case, where the cold energy demand, as well as the electrical power demand, are known and constant in time.

These hypotheses are necessary as the first analysis mainly focuses on describing and designing the main components that constitute the plant system. In future work, it would be possible to analyze the dynamic state, introducing, for instance, the control system that simulates a real control strategy for the plant.

After the previous necessary clarifications, it is possible to describe the model as it is implemented into UniSim ${ }^{\circledR}$ Design Suite.

\subsection{Tank}

The tank is modeled using a standard "Tank" object. The selected shape is cylindrical ( $\mathrm{r}=5$ $\mathrm{m}, \mathrm{H}=10 \mathrm{~m})$ with a total volume of about $785 \mathrm{~m}^{3}$. The $\mathrm{LNG}$ conditions are cryogenic $(\mathrm{T}=$ $160{ }^{\circ} \mathrm{C}, \mathrm{p}=1.14$ bar) to maintain the liquid phase.

The boil-off gas (BOG) flow is generated by the heat transfer process that happens between the liquefied gas and the outdoor. Even if the tank is considered insulated (the thermal conductivity is taken equal to $0.1 \mathrm{~W} / \mathrm{m}^{2} \mathrm{~K}$ ), the external tank surface and the temperature difference are big enough to cause part of the liquefied gas to evaporate.

Moreover, the tank outlets dedicated to bunkering and CNG production are not modeled, because these gas streams do not actively contribute to the plant functioning.

\subsection{Secondary Loops}

The secondary loops are used both to transfer the LNG regasification exergy and the flue gases heat to secondary fluids, in order to fulfill the demands for cold and hot thermal power. However, at this stage of work, a simplified approach to study the secondary loops have been adopted, representing them as heat loads with customizable temperature and hourly heat flow rate profile.

Firstly, it is hypothesized that the heating energy demand (either for district heating or process heating) is not present. This working condition, for instance, can be considered a case during summer functioning mode, or when there is no industrial process that requires a steam distribution line. Operatively, this has been accounted for not describing the hot water loop but introducing a chiller component. Eventually, a certain amount of heat can be removed from the flue gas line directly by the component HX5, lowering the temperature before the exhaust system.

Secondly, the brine loop is not analyzed in detail, and it is modeled as a simple heater where the heat needed for the regasification process is available. In this case, the amount of heat that should be used for the cold thermal power production is exchanged directly in the component HX1. This loop is essential because the regasification process takes place thanks to the heating available at this stage of the plant. After crossing the heat exchanger, the stream of natural gas should be entirely vaporized, thus the gas should be in a superheated state. This is mandatory to avoid the presence of liquid phase gas downstream of the heat exchanger HX1. 


\subsection{Turbine and Compressor System}

The electrical power is produced thanks to a gas turbine, which also operates the compressor used to treat the combustion chamber feeding air. In real machines, the turbine and the compressor are connected by the same motor shaft. In the model, this configuration was described using two different turbines.

The first one, the "High Pressure (HP) Gas Turbine," is designed to produce solely the work needed by the compressor to be operated at the desired conditions.

The second one, namely the "Low Pressure (LP) Gas Turbine," is used to produce the desired amount of electrical energy, which can be used by the designed users.

This model configuration is necessary because UniSim ${ }^{\circledR}$ Design does not allow to split the work produced by the turbine directly, so it was not possible to correctly evaluate the net amount of work produced by the turbine. In Fig. 2, the connection between the turbine motor shaft and the compressor one is described by a logic module in UniSim ${ }^{\circledR}$ Design. This block is denominated "Selector Block," and it was used to redirect the work produced by the HP turbine to the gas cycle compressor shaft.

The Energy fluxes resulting from the simulation are listed in Tab. 1.

Table 1. Heat Fluxes for plant components

\begin{tabular}{|c|c|c|c|l|l|l|l|l|l|}
\hline & & \multicolumn{7}{|c|}{ Stream Name (ref. Fig. 3) } \\
\hline Quantity & Units & $\begin{array}{l}\text { P el } \\
\text { Pump }\end{array}$ & $\begin{array}{l}\text { P el } \\
\text { GC1 }\end{array}$ & $\begin{array}{l}\text { P el } \\
\text { GC2 }\end{array}$ & Q f & Q c & $\begin{array}{l}\text { Q1 } \\
\text { in }\end{array}$ & $\begin{array}{l}\text { Q1 } \\
\text { out }\end{array}$ & P Net \\
\hline $\begin{array}{c}\text { Heat } \\
\text { Flux }\end{array}$ & $\mathrm{kW}$ & 2,1 & 2,3 & 7157,0 & 410,0 & 0,0 & 83,4 & 83,5 & 12335,0 \\
\hline
\end{tabular}

\section{Results}

It is useful to calculate the $E_{p, \text { ratio }}$ parameter to evaluate the performance of the presented plant layout as proposed by Tagliafico et al. [4]. This allows for consistent evaluation of the total primary energy required by the system, to satisfy the energy demands. This quantity is compared to the total primary energy requested to achieve the same useful effects, using standard conversion cycles.

The $E_{p \text {,ratio }}$ can be calculated using Equation (1).

$$
E_{p, \text { ratio }}=\frac{E_{p}}{E_{p, B A U}}
$$

The numerator is expressing the total of primary energy required by the system, namely the primary energy available from the combustion process and the primary energy required for the functioning of the main auxiliary components (LNG pump and BOG compressor). The denominator, on the other hand, is expressing the same quantity but considering the case where the energy demand is satisfied using traditional plants.

Equation (1) gives a solid and easy way to calculate the percentage of primary energy saved thanks to the aforementioned multigeneration plant layout. This indicator is not intended to compare different plant configurations, but it gives an immediate evaluation of the primary energy savings, compared to traditional systems.

The application of Eq. (1) gives a value of $E_{p, \text { ratio }}$ equal to 0.88 . 
As El-Nashar [19] proposed, it is useful to define the Fuel Energy Saving Ratio (FESR) index using Equation (2):

$$
F E S R=1-E_{p, \text { ratio }}
$$

It is possible to calculate the effective saving per MW of primary energy consumed, solving Equation (2), finding a value of FESR equal to 0.12 .

\section{Conclusions and future perspectives}

Analyzing the results obtained in the previous paragraph, it is immediate to notice that the proposed multipurpose plant configuration allows to save $12 \%$ per MW of primary energy consumed, with respect to traditional systems. While the savings alone may not deem worthy to justify the capital investment, some clarifications must be made in order to better understand the framework of this work.

In the first place, the usage of LNG in ports area will be, more likely, a mandatory step in order to reduce air pollution caused by ships, both during navigation as well as during mooring. This is an added value that is not explicitly included in mere thermodynamical evaluations, but it must be accounted for.

In the second place, LNG storage systems are likely to be realized inside seaports, meaning that the investments necessary for their realization and safety measures are already covered. In this way, the multipurpose plant shares part of the initial investment, and the only additional costs are the ones pertaining to its construction.

Lastly, this plant can be considered as a potential part of a more extensive seaport energy network. It can be integrated into an energy management system at local area for energy production optimization. In this way, it could be possible to achieve better energy resources management within ports areas.

In future work, the system will be studied under dynamic conditions, also considering an optimized control strategy able to maximize the energy efficiency of the proposed plant layout. Moreover, the development of a dynamic model will allow to study the effects of long-term unusual working conditions, like those induced by the COVID-19 lockdown period. This is useful to test the robustness of the model in case of long period of unusual working conditions.

\section{References}

[1] “The Role of Gas in Today's Energy Transitions - Analysis - IEA.” [Online]. Available: https://www.iea.org/reports/the-role-of-gas-in-todays-energy-transitions. [Accessed: 10-May-2020].

[2] I. G. Union, “The World LNG Report,” Barcelona, 2020.

[3] C. Dispenza, G. Dispenza, V. La Rocca, and G. Panno, "Exergy recovery during LNG regasification: Electric energy production - Part one," Appl. Therm. Eng., vol. 29, no. 2-3, pp. 380-387, 2009, doi: 10.1016/j.applthermaleng.2008.03.036.

[4] G. Tagliafico, F. Valsuani, and L. A. Tagliafico, "Liquefied natural gas submerged combustion vaporization facilities: process integration with power conversion units," Int. J. Energy Res., vol. 37, no. 1, pp. 80-92, Jan. 2013, doi: 10.1002/er.1937.

[5] M. F. M. Fahmy, H. I. Nabih, and T. A. El-Rasoul, “Optimization and comparative 
analysis of LNG regasification processes," Energy, vol. 91, pp. 371-385, 2015, doi: 10.1016/j.energy.2015.08.035.

[6] S. Li, B. Wang, J. Dong, and Y. Jiang, "Thermodynamic analysis on the process of regasification of LNG and its application in the cold warehouse," Therm. Sci. Eng. Prog., vol. 4, pp. 1-10, Dec. 2017, doi: 10.1016/j.tsep.2017.08.001.

[7] B. B. Kanbur, L. Xiang, S. Dubey, F. H. Choo, and F. Duan, "Cold utilization systems of LNG: A review," Renewable and Sustainable Energy Reviews, vol. 79. Elsevier Ltd, pp. 1171-1188, 2017, doi: 10.1016/j.rser.2017.05.161.

[8] A. Atienza-Márquez, J. C. Bruno, and A. Coronas, "Cold recovery from LNGregasification for polygeneration applications," Appl. Therm. Eng., vol. 132, pp. 463-478, Mar. 2018, doi: 10.1016/j.applthermaleng.2017.12.073.

[9] I. Lee, J. Park, F. You, and I. Moon, “A novel cryogenic energy storage system with LNG direct expansion regasification: Design, energy optimization, and exergy analysis," Energy, vol. 173, pp. 691-705, Apr. 2019, doi: 10.1016/j.energy.2019.02.047.

[10] A. Atienza-Márquez, J. C. Bruno, A. Akisawa, and A. Coronas, "Performance analysis of a combined cold and power (CCP) system with exergy recovery from LNG-regasification," Energy, vol. 183, pp. 448-461, Sep. 2019, doi: 10.1016/j.energy.2019.06.153.

[11] T. He, Z. R. Chong, J. Zheng, Y. Ju, and P. Linga, "LNG cold energy utilization: Prospects and challenges," Energy, vol. 170, pp. 557-568, Mar. 2019, doi: 10.1016/j.energy.2018.12.170.

[12] D. S. Ayoua and V. Eveloy, "Sustainable multi-generation of district cooling, electricity, and regasified LNG for cooling-dominated regions," Sustain. Cities Soc., p. 102219, May 2020, doi: 10.1016/j.scs.2020.102219.

[13] "Emission Control Areas (ECAs) designated under regulation 13 of MARPOL Annex VI (NOx emission control)." [Online]. Available: http://www.imo.org/en/OurWork/Environment/PollutionPrevention/AirPollution/Pa ges/Emission-Control-Areas-(ECAs)-designated-under-regulation-13-ofMARPOL-Annex-VI-(NOx-emission-control).aspx. [Accessed: 11-May-2020].

[14] European Parliament, "Directive (EU) 2018/410 of the European Parliament and of the Council of 14 March 2018 amending Directive 2003/87/EC to enhance costeffective emission reductions and low-carbon investments, and Decision (EU) 2015/1814," Off. J. Eur. Union, vol. L76, October 2003, pp. 3-27, 2018.

[15] B. Y. Yoo, "Economic assessment of liquefied natural gas (LNG) as a marine fuel for $\mathrm{CO} 2$ carriers compared to marine gas oil (MGO)," Energy, vol. 121, pp. 772780, 2017, doi: 10.1016/j.energy.2017.01.061.

[16] J. Eise Fokkema, P. Buijs, and I. F. A. Vis, "An investment appraisal method to compare LNG-fueled and conventional vessels," Transp. Res. Part D Transp. Environ., vol. 56, pp. 229-240, Oct. 2017, doi: 10.1016/j.trd.2017.07.021.

[17] T. Iannaccone, G. Landucci, A. Tugnoli, E. Salzano, and V. Cozzani, "Sustainability of cruise ship fuel systems: Comparison among LNG and diesel technologies," J. Clean. Prod., vol. 260, Jul. 2020, doi: 10.1016/j.jclepro.2020.121069.

[18] P. Lauriola, "Il progetto," 2009. [Online]. Available: http://interregmaritime.eu/web/signal. [Accessed: 20-May-2020].

[19] Ali M. El-Nashar, "Cogeneration for power and desalination - state of the art review”, Desalination, vol. 134, Issues 1-3, pp 7-28, 2001, doi: https://doi.org/10.1016/S0011-9164(01)00111-4. 